\title{
Modelling of Non-linear Shear Displacement Behaviour of Soil-Geotextile Interface
}

\author{
Anubhav ${ }^{1} \cdot$ Haimin $\mathrm{Wu}^{2}$
}

Received: 3 May 2015/Accepted: 21 May 2015/Published online: 30 May 2015

(c) Springer International Publishing AG 2015

\begin{abstract}
Behaviour of reinforced soil structures depends on the material properties of soil and geosynthetics. Apart from individual properties of soil and reinforcement, the interaction between reinforcement and soil also plays important role in deciding the behaviour of reinforced soil structures. The modelling of the interface characteristics is a very important aspect in developing a correct numerical model for predicting the performance of reinforced soil structures. For simulating the interface behaviour a linearly elastic model with Mohr-Coulomb criterion is commonly used. Experimental observations made from direct shear tests usually show that the force-displacement relationship is non-linear till a peak is attained, beyond which softening behaviour is observed. In this paper a constitutive model appropriate for geosynthetic interfaces has been implemented in FLAC ${ }^{3 \mathrm{D}}$ and used to simulate the shear stress displacement behaviour of different sand-geotextile interfaces. In the present study, shear stress-displacement behaviour of interfaces of different types of sands and geotextiles (monofilament woven, multifilament woven and nonwoven) have been considered for simulation. The simulated curves using the FLAC $^{3 \mathrm{D}}$ showed very good agreement with the experimental data over the complete stress-displacement ranges.
\end{abstract}

Anubhav

anubhav@ntpc.co.in

Haimin $\mathrm{Wu}$

wuhaimin@hhu.edu.cn

1 NTPC Ltd., Solapur Super Thermal Power Project, Solapur 413215, Maharashtra, India

2 College of Water Conservancy and Hydropower Engineering, Hohai University, 1 Xikang Road, Nanjing 210098, People's Republic of China
Keywords Geotextile $\cdot$ Interface $\cdot$ Direct shear test . Grain shape $\cdot$ Shear stress $\cdot$ Non-linear model

\section{List of symbols}

A

$c$

$E_{\mathrm{i}}$

$E_{\mathrm{t}}$

K

$m$

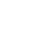

$n$

$P_{\mathrm{a}}$

$R$

$R^{2}$

$R_{\mathrm{f}}$

$\delta$

$\delta_{\mathrm{p}}$

$\sigma_{n}$

$\tau$

$\tau_{\mathrm{p}}$

$\tau_{\mathrm{r}}$

$\tau_{\text {ult }}$

$\phi_{\mathrm{cv}}$

$\phi_{\text {peak }}$ or $\phi_{\mathrm{p}}$
Co-efficient (dimensionless)

Cohesion $(\mathrm{Pa})$

Initial tangent shear modulus $(\mathrm{Pa})$

Tangent modulus $(\mathrm{Pa})$

Modulus number (dimensionless)

Power for stress-level dependency of stiffness (dimensionless)

Modulus exponent (dimensionless)

Atmospheric pressure $(\mathrm{Pa})$

Residual factor (dimensionless)

Coefficient of determination values (dimensionless)

Failure ratio (dimensionless)

Shear displacement (m)

Post peak plastic shear displacement (m)

Normal stress $(\mathrm{Pa})$

Shear strength $(\mathrm{Pa})$

Peak shear strength $(\mathrm{Pa})$

Residual or large deformation shear strength (Pa)

Ultimate shear strength $(\mathrm{Pa})$

Residual or constant volume friction angle (degree)

Peak friction angle (degree)

\section{Introduction}

Performance of geosynthetics reinforced soil retaining walls, slopes and embankments depend on different factors such as properties of backfill soil, reinforcement, facing 
elements etc. Geosynthetic-soil interface properties also play important role in safe and economical design of geosynthetic soil structures. Modelling of stress-displacement behaviour of the soil-geosynthetic interfaces is essential for realistic numerical simulation and failure assessment of such structures. For simulation of post construction large deformations due to progressive failure, modelling of post peak shear stress-displacement behaviour of soil-geosynthetic interface is very critical from stability considerations.

Many researchers incorporated the interface properties in the analysis of reinforced soil structures for realistic simulations [1-5]. In the numerical analysis of the reinforced soil structures, generally linear elastic interface model with Mohr-Coulomb failure criterion is used. Experimental observations showed that the force-displacement relationships of sand-geotextile interfaces are nonlinear in both peak and post-peak ranges [6-12]. For correct predictions of behaviour of the reinforced soil structures, it is also necessary to correctly incorporate the soilgeosynthetic interface behaviour in the numerical models. Based on the results of experiments, researchers have proposed several types of interface constitutive models, including the non-linear elastic model [13], elastic-perfectly plastic model [14, 15], rigid-plastic model [16], elastic-viscoplastic model [17], damage model [18], strainsoftening model, [19, 20], monotonic and cyclic model [21] and cracking model [22], unsaturated interface model [7]. Whereas there are many available interface models, most numerical analysis software typically only provide a single and simple generalized interface model for users.

Therefore, in the present study, a simple non-linear model, which is easy to implement in numerical modelling was incorporated in $\mathrm{FLAC}^{3 \mathrm{D}}$ a finite difference code. The experimental shear stress displacement response of different sand-geotextile interfaces, obtained from direct shear tests, were successfully simulated in FLAC $^{3 \mathrm{D}}$ over complete stress range (pre-peak and post peak).

\section{Integration of Non-linear Interface Model in FLAC}

Due to its distinct advantage of solving large strain geotechnical deformation problems, fast Lagrange analysis of continua in three dimensions ( LLAC $^{3 \mathrm{D}}$ ) has been widely used in geotechnical engineering including modelling of reinforced soil structures. FLAC ${ }^{3 \mathrm{D}}$ provides many built-in constitutive models that can be employed to simulate the complicated mechanical behaviours of different kinds of soils and rocks. It also enables users to implement user-defined models. There are two methods to implement a userdefined model through the development platform of
FLAC $^{3 \mathrm{D}}$. The first method is to implement the model through $\mathrm{VC}++$ programming. Another method is to implement the model using the embedded language (FISH) of FLAC ${ }^{3 \mathrm{D}}$.

FLAC $^{3 \mathrm{D}}$ provides interfaces that are characterized by Coulomb sliding and/or tensile and shear bonding. Interfaces have the properties of friction, cohesion, dilation, normal and shear stiffnesses, and tensile and shear bond strengths. The built-in interface element in $\mathrm{FLAC}^{3 \mathrm{D}}$ can only simulate the relationship between shear stress and shear displacement according to the linear elastic-perfectly plastic model. But it cannot be used to simulate interfaces characterized by non-linear and strain-softening behaviour.

Zhang and $\mathrm{Xu}$ [23] improved the normal calculation method of interface elements in FLAC $^{3 \mathrm{D}}$ to simulate the mechanical behaviour of a joint with initial width. However, no improved constitutive relationships for the interface element have been implemented. Wu et al. [24] developed a procedure to replace the linear elastic portion of the shear stress-shear displacement relationship by a non-linear (hyperbolic) elastic relationship originally developed by Clough and Duncan [13]. The perfectly plastic portion was replaced by a non-linear strain-softening model developed by Esterhuizen et al. [9] for simulation of the non-linear strain-softening behaviour of geosynthetic interfaces after the displacement reaches its peak strength. The stain softening model of Esterhuizen et al. [9] was developed based on the post peak curves obtained for claygeomembrane interfaces. The experimental observations from different studies for sand-geotextile interfaces showed different post-peak stress-displacement relationship as compared to that for clay-geomembrane interfaces. Based on experimental observations, Anubhav and Basudhar [11] modified the procedure developed by Esterhuizen et al. [9] for simulating the stain softening model for sand-geotextile interfaces. In the present study, the modified model is incorporated in FLAC ${ }^{3 \mathrm{D}}$ as described below.

\section{Non-linear Strain Softening Interface Model}

The complete shear-stress displacement behaviour was divided into two segments namely a pre-peak behaviour and a post-peak behaviour (Fig. 1). Peak and large displacement (residual) shear stresses are computed by MohrCoulomb failure envelope or non-linear failure envelopes. For completeness, the model adopted for simulation of shear stress-displacement behaviour of interface is presented below in brief.

\section{Pre Peak Behaviour}

The peak and residual shear stress for the interface are computed from approximately linear failure envelope which can be represented by Mohr-Coulomb criteria: 


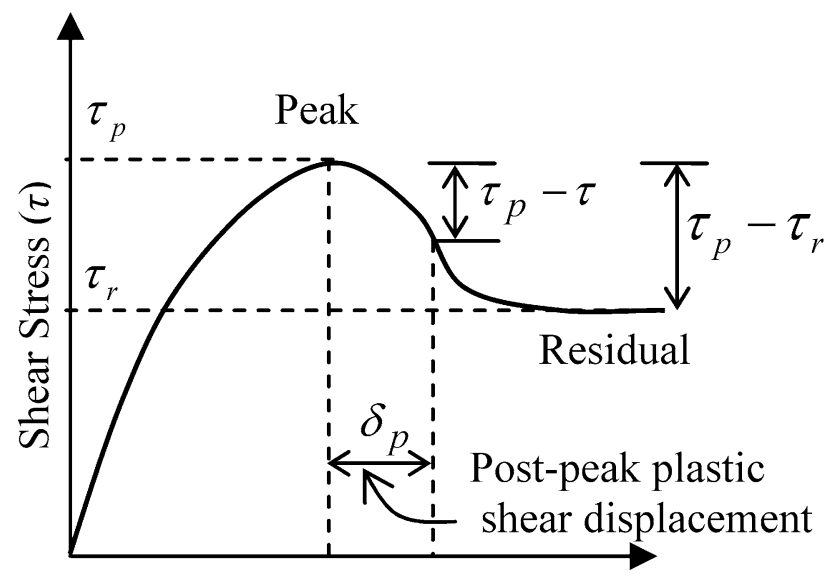

Shear Displacement $(\delta)$

Fig. 1 Generalized stress-displacement relationship for sandgeosynthetic interface

$\tau_{\mathrm{p}}$ or $\tau_{\mathrm{r}}=c+\sigma_{n} \tan \phi$

where $\tau_{\mathrm{p}}=$ peak shear stress, $\tau_{\mathrm{r}}=$ large deformation shear stress, $c=$ apparent cohesion intercept (use $c_{\mathrm{p}}$ for $\tau_{\mathrm{p}}$ and $c_{\mathrm{r}}$ for $\tau_{\mathrm{p}}$ ), $\sigma_{n}=$ normal stress and $\phi=$ friction angle (use $\phi_{\mathrm{p}}$ for $\tau_{\mathrm{p}}$ and $\phi_{\mathrm{r}}$ for $\tau_{\mathrm{p}}$ ).

Duncan and Chang [25] procedure modified by Claugh and Duncan [13] for interface modelling was used for the non-linear pre-peak behaviour at the geosynthetic interface. The instantaneous slope of the shear stress-displacement curve $\left(E_{\mathrm{t}}\right)$ for any normal stress can be expressed by:

$E_{\mathrm{t}}=K P_{\mathrm{a}}\left(\frac{\sigma_{n}}{P_{\mathrm{a}}}\right)^{n}\left[1-R_{\mathrm{f}} \frac{\tau}{c+\sigma_{n} \tan \phi}\right]^{2}$,

and

$\tau=\frac{\delta}{\frac{1}{E_{\mathrm{i}}}+\frac{\delta}{\tau_{\mathrm{ult}}}}$,

where, $\tau=$ shear stress, $\delta=$ shear displacement, $E_{\mathrm{i}}=$ initial tangent shear modulus, $\tau_{\text {ult }}=$ ultimate shear strength, $K=$ modulus number, $n=$ modulus exponent, both are dimensionless numbers and $P_{\mathrm{a}}=$ atmospheric pressureVariation of $\tau_{\text {ult }}$ with normal stress is accounted for by correlating failure shear stress obtained by Mohr-Coulomb criteria to it as:

$\tau_{\mathrm{p}}=R_{\mathrm{f}} \cdot \tau_{\mathrm{ult}}$,

where, $R_{\mathrm{f}}=$ failure ratio and as $\tau_{\text {ult }}$ is always smaller than $\tau_{\mathrm{p}}$, the value of $R_{\mathrm{f}}$ will always be less than unity.

Pre-peak interface behaviour can be well represented by above hyperbolic model. For obtaining peak shear strength both Mohr-Coulomb failure envelope (Eq. 1) have been used.

\section{Post Peak Behaviour}

The post peak shear strength reduction $\left(\tau_{\mathrm{p}}-\tau\right)$, post peak plastic shear displacement $\delta_{\mathrm{p}}$ are defined in Fig. 1. Post peak shear strength reduction $\left(\tau_{\mathrm{p}}-\tau\right)$ is normalized by the shear strength reduction from peak to residual value $\left(\tau_{\mathrm{p}}-\tau_{\mathrm{r}}\right)$, represented by residual factor [26]:

$R=\frac{\tau_{\mathrm{p}}-\tau}{\tau_{\mathrm{p}}-\tau_{\mathrm{r}}}$.

From the experimental observation of geotextile-sand interface, relationship between plastic shear displacement and residual factor (normalized shear strength degradation, $R$ value ranging from 0 to 1 ) was proposed to be represented by following equation:

$R=1-\exp \left(-A \cdot \delta_{\mathrm{p}}^{\mathrm{z}}\right)$

The above equation is commonly used for growth and decay process. This equation is similar to the expressions suggested for computing the disturbance function in case of Disturbed state concept models [27].

The shear stress- displacement data obtained from direct shear test can be used to determine the residual factor values (normalized shear strength degradation) with variation of plastic shear displacement beyond peak for different normal stresses. The coefficient $A$ and $z$ for Eq. (6) can be obtained by fitting the curve to above data using non-linear regression analysis.

\section{Steps of Implementation of Model in FLAC ${ }^{3 D}$}

The constitutive relation of the non-linear strain-softening interface model was incorporated into FLAC ${ }^{3 \mathrm{D}}$ by the userdefined FISH program. The detailed program flow chart of implementation of interface model in $\mathrm{FLAC}^{3 \mathrm{D}}$ is shown in Fig. 2. The general steps of implementation is as follows.

At every calculation step, the program first inputs model parameters and reads the normal effective stresses, shear stresses and shear displacements of every interface element. The state of every interface element is judged by the yield criterion according to the shear stresses and shear displacements. According to the state of the interface element, constitutive relations of corresponding stage are selected to calculate the relevant stiffness $\left(E_{\mathrm{t}}\right)$ and strength parameters $(\varphi$ and $c$ ) of the non-linear strain softening interface mode. Then the calculated new parameters are inputted to the interface element to carry out the calculation of next step. In this way, the program continuously circulates until all elements reach an equilibrium state. Due to the limit of length for this paper, the source code of the program cannot be presented in detail. 
Fig. 2 Program flow chart for implementation of non-linear strain softening interface model into interface element of FLAC $^{3 \mathrm{D}}$

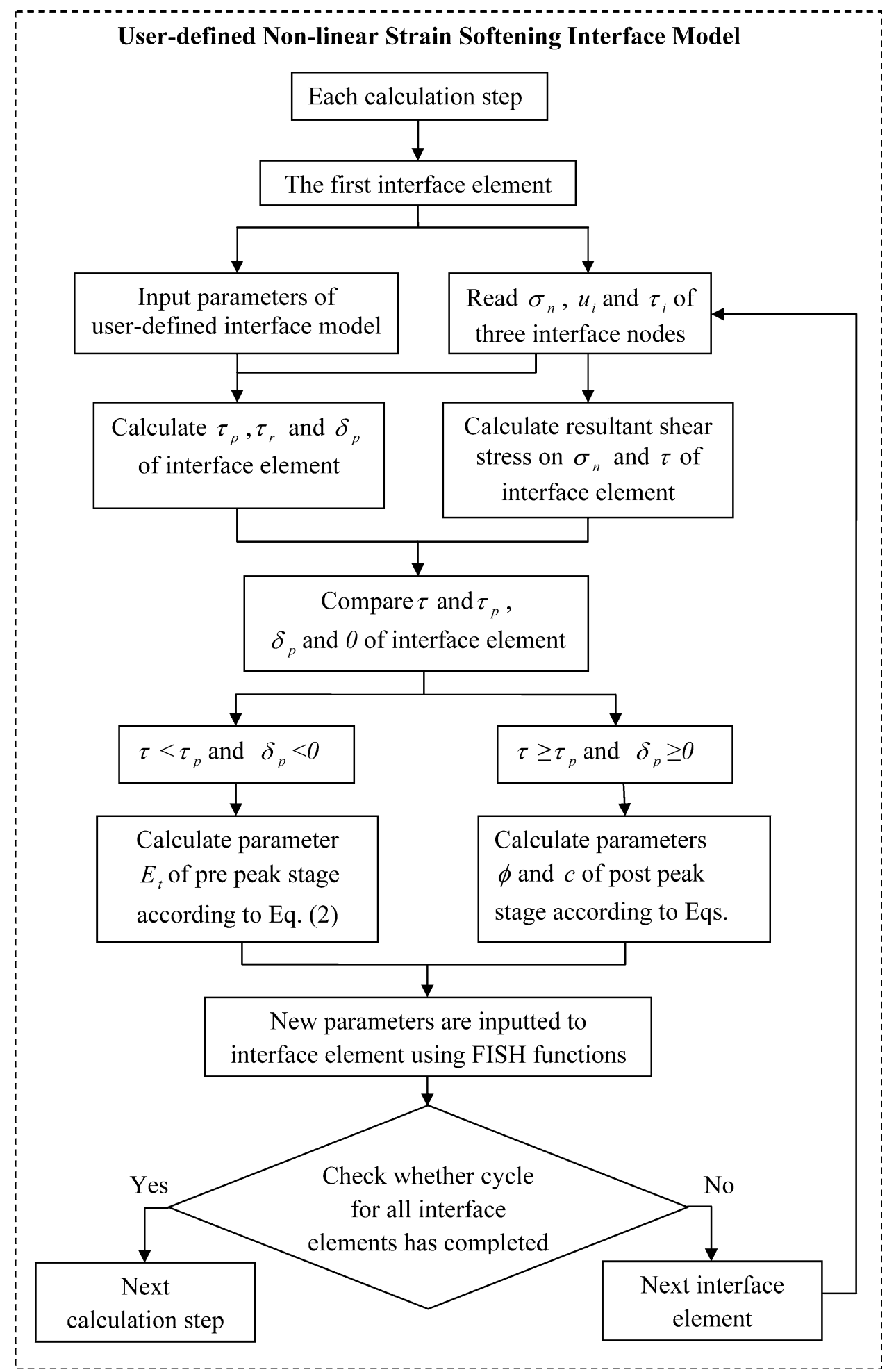

\section{Model Validation}

For validation of the developed procedure, a model of direct shear test was created in FLAC ${ }^{3 \mathrm{D}}$ (Fig. 3). The model composed of two parts, the upper part represents the shear box with soil and lower part represents a solid block on which geotextile is glued. Lower block was made larger than the upper box to maintain constant area of contact between soil and geotextile. Liner elastic model was used for soil in upper box and lower solid box. Gravity forces were not 


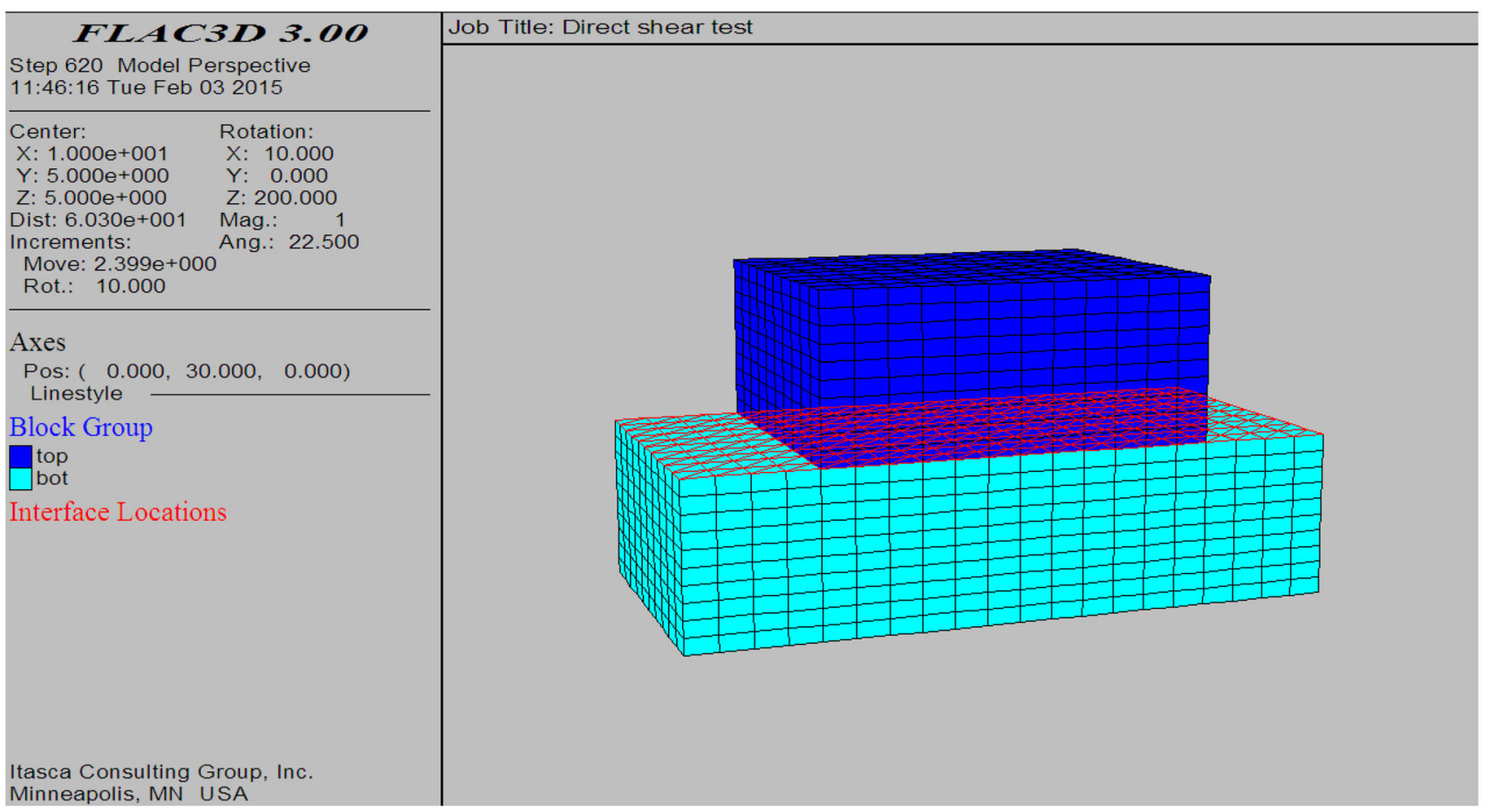

Fig. 3 FLAC $^{3 \mathrm{D}}$ model for simulation of interface testing

considered in the numerical modelling. Direct shear test was simulated by applying a constant normal stress on the top of soil surface and then applying fixed horizontal velocity to all the elements of upper part for displacement of upper soil block. In the present study the non-linear model was verified using the published experimental results of direct shear tests conducted by Anubhav and Basudhar [12]. Experiments were conducted in a conventional size modified direct shear box using two sands having different shaped grains (one having angular grains-Kalpi Sand and other having rounded grains-Ennore Sand). Both are medium sand and can be classified as poorly graded sand (group symbol-SP) as per Unified Classification System. Two different multifilament woven geotextiles (CTG-A \& CTG-B) were used in the experiments. CTG-A geotextile has practically identical properties in both $\mathrm{m} / \mathrm{c}$ and cross $\mathrm{m} / \mathrm{c}$ direction therefore interface shear tests were conducted with CTG-A geotextile placed in only the $\mathrm{M} / \mathrm{c}$ direction. Whereas properties of CTG-B geotextile in the two directions are quite different, therefore for CTG-B geotextile interface shear tests were conducted with placing the geotextile in both the directions.

Another experimental study presented by Lee and Manjunath [6] for interface behaviour of medium-grained, uniform sand and three varieties of woven and non-woven geotextiles using a large size direct shear box. Out of these, complete shear stress-displacement response of monofilament woven geotextile (Amoco 2000) and sand interface for four normal stresses were reported in the paper and same were also considered for simulation. They reported that sand-Amoco 2000 interface showed a considerable decrease in the post-peak shear stresses but constant shear stress at large displacements were not observed even with the end of $30 \mathrm{~mm}$ of shear. The residual shear stress tends to show a gradual and steady increase until the end of sharing. They attributed this increase in shear stress to the presence of high friction griper plate below the geotextile and its contact to the fine soil grains passing through the damaged geotextile openings. It was also reported that the residual friction angles obtained by conducting multiple reversal tests with two to three cycles and shear displacements of $20 \mathrm{~mm}$ were applied. However, only one shear stress-displacement curve was given; therefore, beyond peak, the lowest observed shear stress values have been considered as the residual shear stresses.

Miyamori et al. [28] presented an experimental study of interface behaviour of non-woven geotextile and sand using large size shear box. The soil used in the test was poorly graded and sub-angular river sand from which coarse and the fine particles were removed. One of cases for which behaviour was similar to that observed for woven geotextiles-sand interfaces has been considered for simulation with non-linear model in present study.

\section{Determination of the Model Parameters}

For all the cases linear Mohr-Coulomb failure criteria is used to predict both peak and residual shear strength parameters (Table 1). Using the procedure, as described 
above, the parameters, to define pre-peak shear stressdisplacement behaviour, were obtained for each case and are mentioned in the Table 2. The parameters so obtained were used to predict pre-peak shear stress-displacement curves with varying normal stresses for various geotextiles and sand interfaces.

To model the post peak behaviour, residual factors (normalized shear strength degradation, R) were calculated from the experimental data and plotted against plastic shear displacement beyond peak $\left(\delta_{\mathrm{p}}\right)$. The coefficients $A$ and $z$ appearing in Eq. (6) were obtained by non-linear regres- sion analysis using $\boldsymbol{c f t o o l}$ (Curve Fitting Tool) available in MATLAB. Curve Fitting Tool is an interactive environment presented in the form of a graphical user interface. It allows fitting a variety of library or custom models to the data generating relevant regression statistics.

For different geotextiles and sand interfaces, the experimental values and fitted curves between $R$ and $\delta_{\mathrm{p}}$ [using Eq. (6)] are shown in Figs. 4, 5 and 6. Very good fit were obtained for CTG-A \& CTG-B (m/c direction) and Kalpi sand interfaces as indicated by their respective coefficient of determination values $\left(R^{2}\right)$. A reasonably good

Table 1 Shear strength parameters for interfaces

\begin{tabular}{|c|c|c|c|c|c|}
\hline \multicolumn{2}{|l|}{ Interface } & \multicolumn{2}{|c|}{ Peak strength parameters } & \multicolumn{2}{|c|}{ Residual strength parameters } \\
\hline Sand & Geotextile & $c_{\mathrm{p}}(\mathrm{kPa})$ & $\phi_{\mathrm{p}}\left({ }^{\circ}\right)$ & $c_{\mathrm{r}}(\mathrm{kPa})$ & $\phi_{\mathrm{r}}\left({ }^{\circ}\right)$ \\
\hline $\begin{array}{l}\text { Kalpi sand } \\
\text { (Angular) }\end{array}$ & Multifilament woven CTG-A & 0 & 39.3 & 0 & 31 \\
\hline $\begin{array}{l}\text { Kalpi sand } \\
\text { (Angular) }\end{array}$ & Multifilament woven CTG-B (M/c Direction) & 0 & 41.1 & 0 & 33.4 \\
\hline $\begin{array}{l}\text { Kalpi sand } \\
\text { (Angular) }\end{array}$ & Multifilament woven CTG-B (Cross M/c Dir.) & 0 & 40.2 & 0 & 30.7 \\
\hline $\begin{array}{l}\text { Ennore sand } \\
\text { (Rounded) }\end{array}$ & Multifilament woven CTG-A & 0 & 35.8 & 0 & 29.0 \\
\hline $\begin{array}{l}\text { Ennore sand } \\
\text { (Rounded) }\end{array}$ & Multifilament woven CTG-B (M/c Dir.) & 0 & 34.4 & & 28.6 \\
\hline $\begin{array}{l}\text { Ennore sand } \\
\text { (Rounded) }\end{array}$ & Multifilament woven CTG-B (Cross M/c Dir.) & 0 & 34.5 & 0 & 28.3 \\
\hline Medium grained uniform sand & Monofilament woven geotextile & 1.7 & 32.0 & 0 & 30.3 \\
\hline Poorly praded subangular sand & Nonwoven geotextile & 10 & 40.0 & 5.8 & 33.5 \\
\hline
\end{tabular}

Table 2 Model parameters for pre-peak and post-peak behavior

\begin{tabular}{|c|c|c|c|c|c|c|}
\hline \multicolumn{2}{|l|}{ Interface } & \multicolumn{3}{|c|}{ Pre-peak model parameters } & \multicolumn{2}{|c|}{ Post-peak model parameters } \\
\hline Sand & Geotextile & $K$ & $R_{\mathrm{f}}$ & $n$ & $A$ & $z$ \\
\hline $\begin{array}{l}\text { Kalpi sand } \\
\text { (Angular) }\end{array}$ & Multifilament woven CTG-A & 1497 & 0.57 & 0.11 & 1.567 & 1.500 \\
\hline $\begin{array}{l}\text { Kalpi sand } \\
\text { (Angular) }\end{array}$ & Multifilament woven CTG-B (M/c Direction) & 1736.4 & 0.63 & 0.323 & 0.5413 & 1.544 \\
\hline $\begin{array}{l}\text { Kalpi sand } \\
\text { (Angular) }\end{array}$ & Multifilament woven CTG-B (Cross M/c Dir.) & 1613.7 & 0.59 & 0.483 & 1.758 & 1.644 \\
\hline $\begin{array}{l}\text { Ennore sand } \\
\text { (Rounded) }\end{array}$ & Multifilament woven CTG-A & 2573.9 & 0.76 & 0.50 & 0.2432 & 1.660 \\
\hline $\begin{array}{l}\text { Ennore sand } \\
\text { (Rounded) }\end{array}$ & Multifilament woven CTG-B (M/c Dir.) & 2226.5 & 0.78 & 0.221 & 0.166 & 2.062 \\
\hline $\begin{array}{l}\text { Ennore sand } \\
\text { (Rounded) }\end{array}$ & Multifilament woven CTG-B (Cross M/c Dir.) & 2273.4 & 0.72 & 0.562 & 0.32 & 1.65 \\
\hline Medium grained uniform sand & Monofilament woven geotextile & 574.6 & 0.82 & 0.97 & 0.243 & 1.85 \\
\hline Poorly graded subangular sand & Nonwoven geotextile & 1414 & 0.73 & 0.43 & 0.243 & 1.85 \\
\hline
\end{tabular}



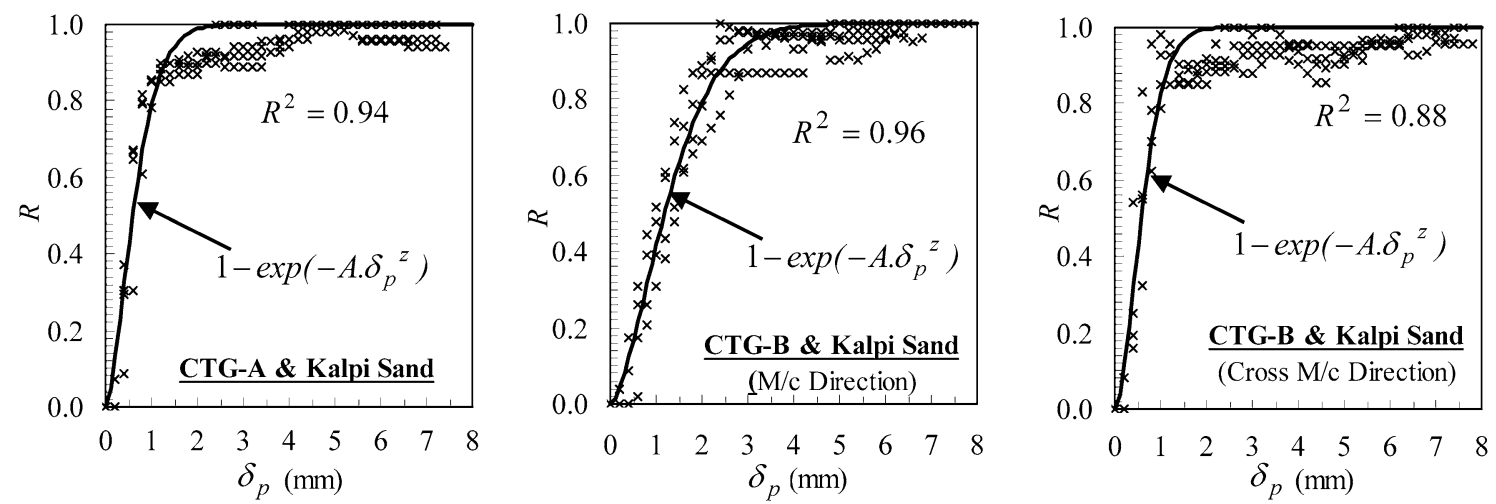

Fig. 4 Normalized strength degradation with plastic displacement (geotextile-Kalpi sand interface)
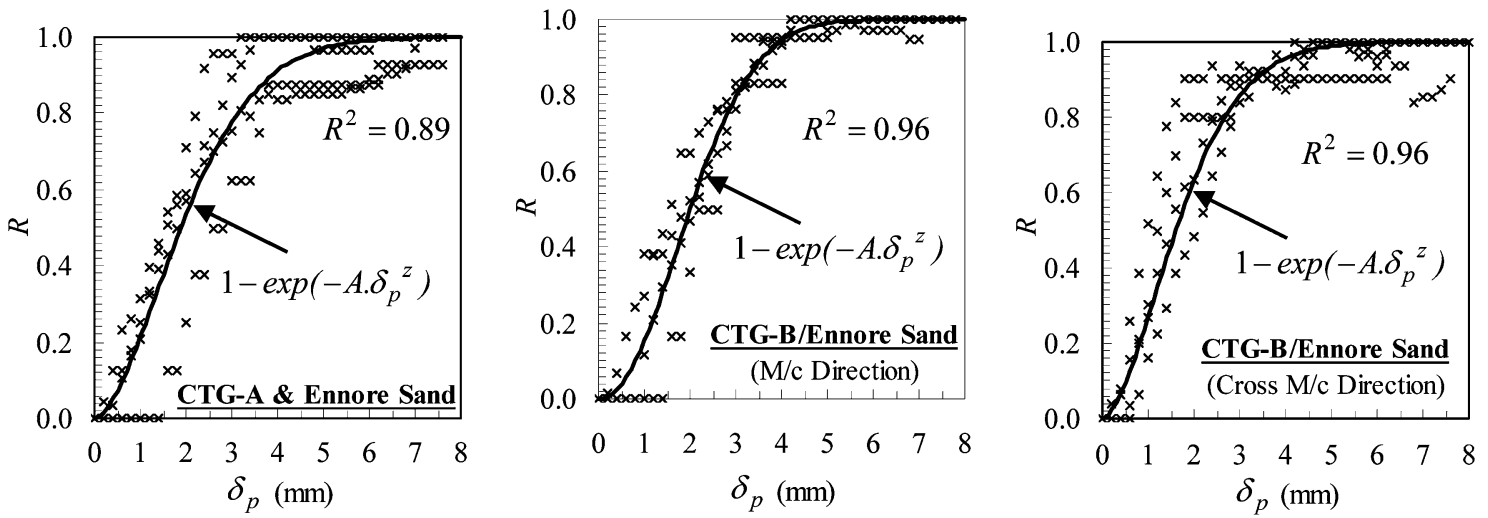

Fig. 5 Normalized strength degradation with plastic displacement (geotextile-Ennore sand interface)
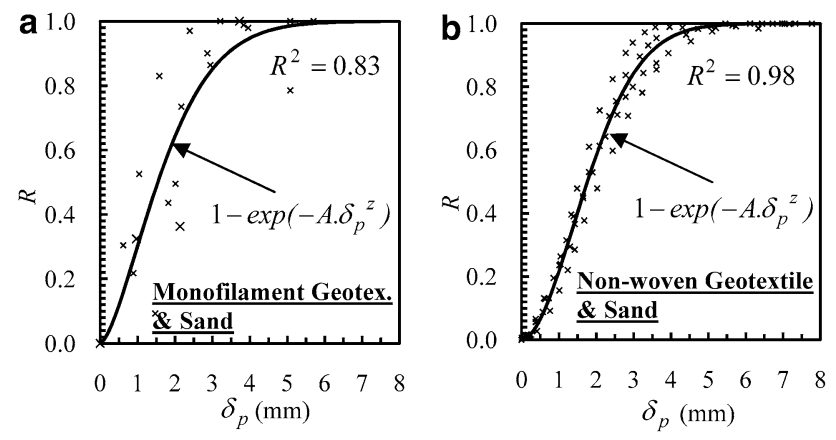

Fig. 6 Normalized strength degradation with plastic displacement: a Monofilament geotextile-sand interface, b Nonwoven geotextilesand interface

fit was obtained for CTG-B (cross $\mathrm{m} / \mathrm{c}$ direction)/Kalpi Sand interface also, with $R^{2}$ equal to 0.88 (Fig. 4).

Excellent fit were obtained for CTG-B (both directions) and Ennore sand interfaces with $R^{2}$ equal to 0.96 and a good fit was obtained for CTG-A/Ennore sand as indicated $R^{2}$ value as 0.89 (Fig. 5).
To obtain post-peak modelling parameters for monofilament geotextile and sand interface, experimental curves were considered till they attain minimum value beyond peak. The gradual increase in the shear stress beyond maximum stress degradation points were not considered for obtaining post-peak modelling parameters. For the selected portion of the experimental curves, residual factors (normalized shear strength degradation, $R$ ) were plotted against plastic shear displacement beyond peak $\left(\delta_{\mathrm{p}}\right)$ and parameters $A$ and $z$ were obtained by curve fitting (Fig. 6a). In this case also a reasonably fair fit with $R^{2}=0.83$ is obtained using Eq. (6).

To model pre-peak behaviour of non-woven geotextile (thin fabric) and sand interface, $R$ and $\delta_{\mathrm{p}}$ as obtained from digitized shear stress-displacement curves are plotted in Fig. 6b. Using Eq. (6) best curve was fitted and post-peak model parameters $(A$ and $z$ ) were obtained for non-woven geotextile (thin fabric) and sand interface (Fig. 6b). In this case excellent fit $\left(R^{2}=0.83\right)$ of the data is obtained using Eq. (6). 


\section{Simulation of Shear Displacement Behaviour}

Using the model parameters given in the Tables 1 and 2 complete shear stress-displacement relationship was predicted for different normal stresses for multifilament woven geotextile and Kalpi Sand interfaces. The comparison of experimental results and numerically simulated curves for different geotextiles and Kalpi sand interfaces are shown in Fig. 7 exhibiting excellent agreement. Interfaces of Kalpi sand with CTG-A and CTG-B (cross-machine direction) show appreciable strain softening response compared to that with CTG-B in machine direction. Form Fig. 7 it is seen that such strain softening response can also be effectively modeled.

The parameters so obtained (Tables 1,2) were used to predict the complete shear stress-displacement curves with varying normal stresses for multifilament woven geotextiles-Ennore Sand interfaces. The comparison of experimental results and fitted curves for different interfaces are shown in Fig. 8 exhibiting excellent agreement in both pre-peak and post-peak regions. Appreciable strain softening response is seen for Ennore sand and geotextile interfaces also, however, the post-peak curves are relatively flat as compared to Kalpi sand interfaces. The post-peak softening will continue for larger displacement before attaining constant large displacement strength (residual strength). In these cases also the modeled behaviour shows excellent agreement with the experimental observations.

The experimental and numerically simulated curves for monofilament geotextile-sand interface for different normal stresses are shown in Fig. 9a. Unlike other cases considered in this study, for this case the experiments were conducted in large shear box. Very good simulation of the experimental
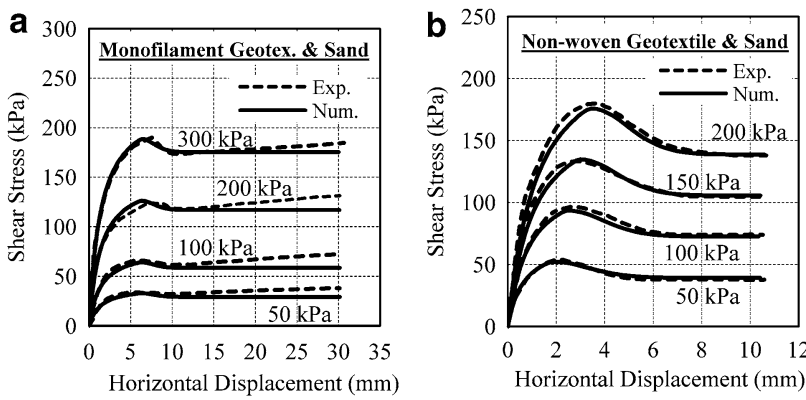

Fig. 9 Predicted and experimental interface behaviour: a Monofilament geotextile-sand interface, b Nonwoven geotextilesand interface
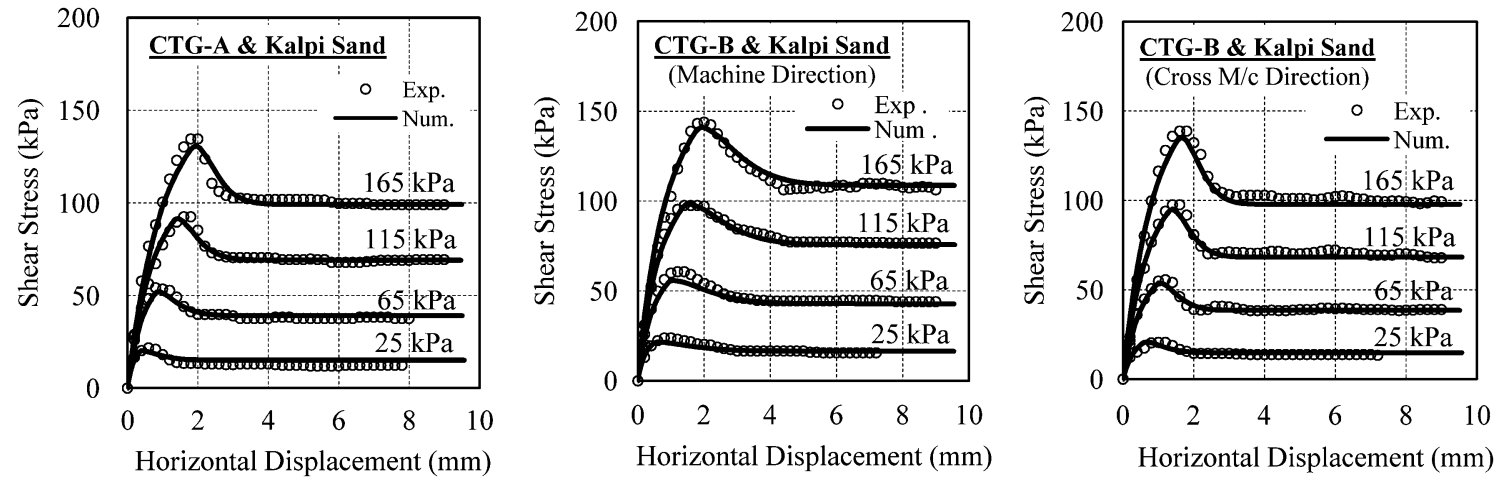

Fig. 7 Predicted and experimental geotextiles-Kalpi sand interface behaviour
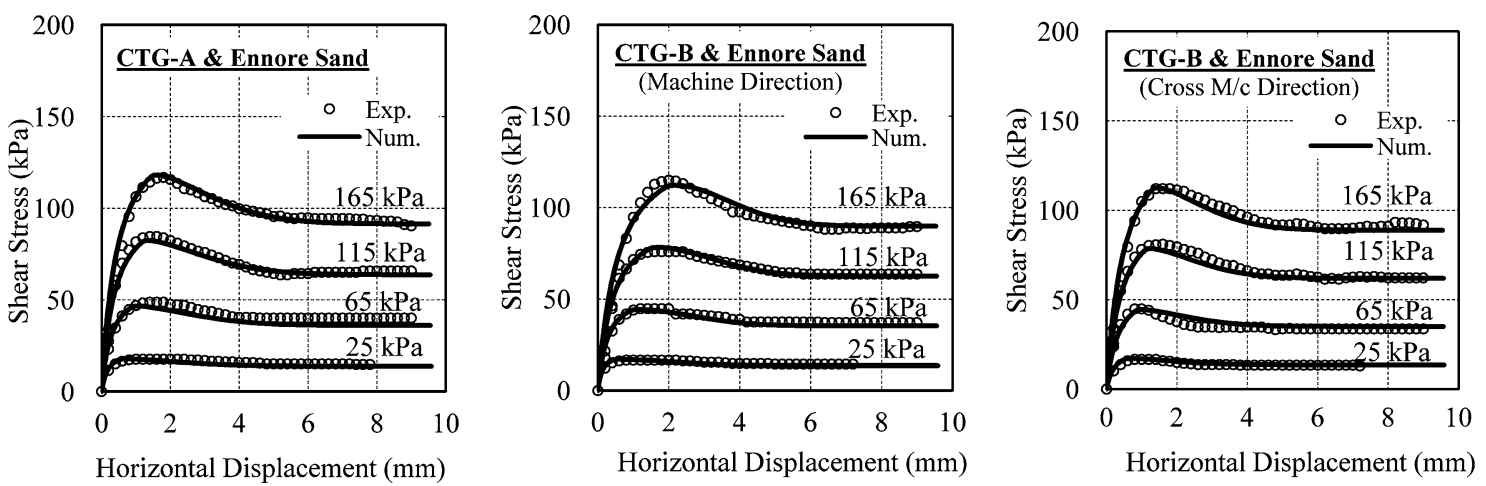

Fig. 8 Predicted and experimental geotextiles-Ennore sand interface behaviour 
data in the pre-peak region is observed for the interface. In post-peak region also, the simulation is quite good. However, the increasing trend of shear stress beyond residual stress point was not simulated by the above procedure. The constant residual angle was considered in the present analysis, as the authors considered this increase in shear stress as an error due to the presence of high friction griper plate below the geotextile and its contact to the fine soil particles passing through the damaged geotextile openings.

Pre and Post Peak model parameters as obtained for nonwoven geotextile (thin fabric) and sand (Tables 1, 2) are used to simulate complete shear stress-displacement curves for different normal stresses. The experimental data and numerically simulated curves for nonwoven geotextile and sand are shown in Fig. 9b. It is observed that complete response of interface of nonwoven geotextile (thin fabric) and sand can also be simulated quite accurately by proposed modelling procedure.

\section{Conclusions}

The paper presents the simulation of non-linear stress-displacement behaviour of sand-geotextile interface for different types of geotextiles and sands. A non-linear strainsoftening model was incorporated into $\mathrm{FLAC}^{3 \mathrm{D}}$ to simulate the non-linear and strain-softening behaviour of sand-geotextile interfaces. Numerical simulations of number of direct shear tests have been done to verify the modelling procedure.

The developed procedure excellently predicted the interface behaviour over the complete range of displacement irrespective of the type of the used sands (angular or rounded) or type of geotextile (Monofilament Woven, multifilament woven and non-woven). For multifilament woven geotextiles under consideration the developed procedure excellently back predicted the experimental behaviour. Very good simulation of the experimental behaviour of the monofilament geotextile and sand was obtained. The developed procedure also predicted the experimental direct shear interface shear stressdisplacement behaviour (both pre-peak and large displacement) for thin non-woven geotextile.

The soil-geosynthetics interface behaviour depends on specific properties of geotextile and soil; which may not follow the generalized shear stress displacement behaviour as shown in Fig. 1. In such cases the proposed method may not be able to simulate the stress-displacement behaviour of interfaces.

\section{References}

1. Krieger J, Thamm BR (1991) Studies of failure mechanism and design method for geotextile-reinforced soil walls. Geotext Geomembr 10(1):53-63
2. Karpurapu R, Bathurst RJ (1995) Behavior of geosynthetic reinforced soil retaining walls using the finite element method. Comput Geotech 17:279-299

3. Desai CS, El-Hoseiny KE (2005) Prediction of field behavior of reinforced soil wall using advanced constitutive model. J Geotech Geoenviron Eng 131(6):729-739

4. Bergado DT, Teerawattanasuk C (2008) 2D and 3D numerical simulations of reinforced embankments on soft ground. Geotext Geomembr 26(1):39-55

5. Wu H, Shu Y (2012) Stability of geomembrane surface barrier of earth dam considering strain-softening characteristic of geosynthetic interface. KSCE J Civ Eng 16(7):1123-1131

6. Lee KM, Manjunath VR (2000) Soil-geotextile interface friction by direct shear test. Can Geotech J 37(1):238-252

7. Khoury CN, Miller GA, Hatami K (2011) Unsaturated soilgeotextile interface behaviour. Geotext Geomembr 29(1):17-28

8. Frost JD, Han J (1999) Behavior of interfaces between fiberreinforced polymers and sands. J Geotech Geoenviron Eng 125(8):633-640

9. Lopes ML, Silvano R (2010) Soil/geotextile interface behaviour in direct shear and pullout movements. Geotech Geol Eng 28(6):791-804

10. Abu-Farsakh M, Coronel J, Mingjiang T (2007) Effect of soil moisture content and dry density on cohesive soil-geosynthetic interaction using large direct shear tests. J Mater Civ Eng 19(7):540-549

11. Anubhav, Basudhar PK (2010) Modeling of soil-woven geotextile interface behavior from direct shear test results. Geotext Geomembr 28(4):403-408

12. Anubhav, Basudhar PK (2013) Interface behaviour of woven geotextile with rounded and angular particle sand. J Mater Civ Eng 25(12):1970-1974

13. Clough GW, Duncan JM (1971) Finite element analysis of retaining wall behavior. J Soil Mech Found Eng 97(12):1657-1672

14. Brandt JRT (1986) Behavior of soil concrete interface. Dissertation, The University of Alberta

15. Zhou AZ, Lu TH (2009) Elasto-plastic constitutive model of soilstructure interface in consideration of strain softening and dilation. Acta Mech Solida Sin 22(2):171-179

16. Yin ZZ, Zhu H, Xu GH (1995) A study of deformation in the interface between soil and concrete. Comput Geotech 17(1):75-92

17. Qian JH, Zhan ML (1993) Tests and analysis on rheological characteristic of interface. In: Proceedings of research on interaction between soil and hydraulic Structures. China Water Power Press, Beijing, (in Chinese)

18. Hu L, Pu JL (2003) Application of damage model for soilstructure interface. Comput Geotech 30(2):165-183

19. Esterhuizen JJB, Fliz GM, Duncan JM (2001) Constitutive behavior of geosynthetic interface. J Geotech Geoenviron Eng 127(10):834-840

20. Kim D (2007) Multi-Scale assessment of geotextile-geomembrane interaction. Dissertation, Georgia Institute of Technology, Atlanta

21. Zhang G, Wang LP, Zhang JM (2008) Unified modeling of monotonic and cyclic behavior of interface between structure and gravelly soil. Soils Found 48(2):231-245

22. Caballero A, Willam KJ, Carolc I (2008) Consistent tangent formulation for 3D interface modeling of cracking/fracture in quasi-brittle materials. Comput Methods Appl Mech Eng 197(33-40):2804-2822

23. Zhang GK, Xu WY (2005) Numerical simulation of discontinuous contact behavior of vertical construction joints in gravity dam. J Hydraul Eng 36(8):982-987 (in Chinese)

24. Wu H, Shu Y, Zhu J (2011) Implementation and verification of interface constitutive model in FLAC ${ }^{3 \mathrm{D}}$. Water Sci Eng 4(3): $305-316$ 
25. Duncan JM, Chang CY (1970) Nonlinear analysis of stress and strain in soils. J Soil MechFound Div 96(5):1629-1653

26. Skempton AW (1964) Long term stability of clay slopes. Géotechnique 14(2):77-101

27. Park IJ, Desai CS (2000) Cyclic behavior and liquefaction of sand using disturbed state concept. J Geotech Geoenviron Eng ASCE 126(9):834-846
28. Miyamori T, Iwai S, Makiuchi K (1986) Frictional characteristics of non-woven fabrics. In: Third international conference on geotextiles, Vienna, pp 701-705 